\title{
The Use of Double Y - Shaped versus Conventional Titanum Miniplates in Fixation of Anterior Mandibular Fractures
}

\author{
Mohamed S. Khairi ${ }^{1}$, Nagy Elprince ${ }^{2}$, Magued H. Fahmy ${ }^{2}$ \\ ${ }^{1}$ B.D.S. Faculty of Dentistry, Liaquat University of Medical \& Health Sciences, Jamshoro- Pakistan \\ ${ }^{2}$ Professor of Oral \& Maxillofacial Surgery Surgery Faculty of Dentistry Alexandria University
}

\begin{abstract}
Introduction:Anterior mandibular fracture rated between $23 \%$ to $36 \%$ of mandibular fracture, it anatomical location and muscle insertion can affect the frequents involvement.Objectives:This work aims at Compare clinically and radiographicallythe use of double Y-shaped titanium mini plate versus 2 straight titanium mini plates in treatment of anterior fracture of the mandible.Material and methods: A prospective study was conducted on a total number of 14 adult patients, who are suffering from mandibular fractures including (Symphyseal and parasymphyseal fractures), indicated for open reduction and internal fixation. the fracture was exposed throw trans oral vestibular incision and reduced under general anesthesia, temporarily maxillomandibular fixation was done using 26 gauge stainless steel wires with arch bar, one double $Y$ shaped mini plated fixed by 6 screws for group A, and 2 conventional mini plates fixed by 8 to 10 screws for group B.Results: Pain, edema and trismus decreased gradually through the follow up period, state of occlusion, condition of the teeth at fracture line, surgical wound healing was perfect at all cases and sensory nerve function one patient had parathesia in first month, decreased throw the follow up time, maximum interincisal mouth opening increased significantly throw the period. Postopertive panorama and cone beam CT showed the adequate reduction and bine healing on fracture line. There was no postoperative complication occurred.Conclusion:It has been shown that double $Y$ - shaped mini plates have same stabilization due to it's configuration as conventional mini plates in fixation of simple anterior mandibular fractures.
\end{abstract}

Keywords: anterior mandibualar fracture, double Y shaped mini plates.

\section{Introduction}

Mandible is the second most commonly fractured bone in the maxillofacial region because of its prominence and position. However there is wide variance in the reported percentage of fractures of the mandible that occur in the anterior mandible, studies done in Kenya, Nigeria, Egypt, Canada and India places this at approximately $23 \%$ to $36 \%$ of allmandibular fractures[1-8].

Anterior mandibular fractures (AMFs) are defined as mandibular fractures that involve a region bounded bilaterally by vertical lines just distal to the canineteeth (the parasymphysis) or linear fractures that run in the midline of the mandible (symphysis)[9].

The lag-screw technique in maxillofacial surgery was first advocated by Brons and Boering in 1970 [10].

Internal fixation of mandibular fractures with miniplates (in conformity with the tension band principle)was first introduced by Michelet in 1973 and was latermodified by Champy et al [11]advised the use of 2 miniplates in the anterior region, one at the inferior border and the second 5 $\mathrm{mm}$ above the lowerplate. Champy's principle is still followed, but the need for 2 miniplates in the parasymphysis region is questioned when a mandibular arch bar is additionally placed simultaneously for intra- or postoperative intermaxillary fixation (IMF). The arch bar placed for intraoperative or postoperative IMF itself acts as a tension band, and the subapical plate (tension band plate) can be eliminated. Because a single miniplate is used instead of 2 plates, the approach is economical, will reduce the incidence of infection, will reduce the incidence of mental nerve injury,may reduce injury to the roots of the anterior teeth,and will diminish wound dehiscence.

The use of 3-dimensional (3D) plates system has been one of themethods of fixation of mandibular fractures challenging the Champy technique for the fixation.T he 3D plates can be considered a 2-plate system, with 2 miniplates joined by interconnecting crossbars[12].Because the screws are arranged in the configuration of a box on both sides of the fracture, a broadband platform is created, increasing the resistance to twisting and bending of the long axis of the plate[13].There is a simultaneous stabilization of the tension and compression zones, making 3D plates a time saving alternative to conventional miniplates. Moreover, this system is simple to apply because of its malleability, low profile(reduced palpability), and ease of application(requiring little or no additional contouring).

As same as in $3 \mathrm{~d}$ plate system, shaped plate as double Y shaped plate consider as 1 mini plate ether than use 2 plates in fixation, with save of compression and tension load, double y shaped mini plates should as most plate stable under load in mandibular fracture[14].

\section{Material and Methods}

\section{Study Design}

A prospective study was conducted on a total number of 14 adult patients, who are suffering from mandibular fractures including (Symphyseal and parasymphyseal fractures). 
All patients were selected from those admitted to the department of Oral \& Maxillofacial surgery and will be operated in Oral \& Maxillofacial surgery department, Faculty of Dentistry, Alexandria University.

They were divided equally into two groups.

Group A (study group): will be treated using

1. $2.0 \mathrm{~mm}$ double Y-shaped Titanium miniplate $(3 \mathrm{x} 3$ holes). (Figure 1)

2. $2.0 \mathrm{~mm}$ mini screws (Monocortical7 $\mathrm{mm}$ length and monocortical $9 \mathrm{~mm}$ length).

3. $2.0 \mathrm{~mm}$ drill pit.

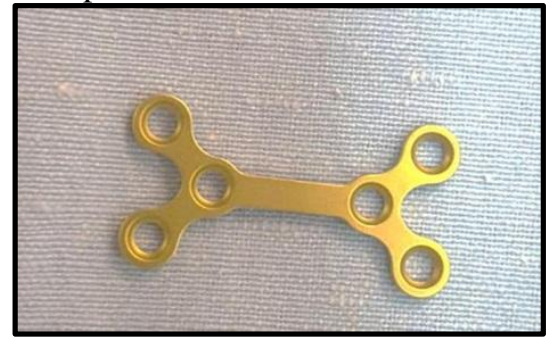

Figure (1): Double Y shaped mini plate.

\section{Group B (Control group): will be treated using:}

1. $2.0 \mathrm{~mm}$ straight mini plates at lower border.

2. $2.0 \mathrm{~mm}$ straight mini plate at $4-5 \mathrm{~mm}$ above.

3. $2.0 \mathrm{~mm}$ mini screws.

4. $2.0 \mathrm{~mm}$ drill pit.

The titanium is the metal of choice for fixation plates; mainly because of its high biocompatibility and ease of manipulation. Modification of miniplates like titanium in duble Y- shaped plating system was developed to meet the requirements of semi rigid fixation with lesser complications.

\section{Inclusion criteria}

- Patients with recent mandibular fractures.

- Dentate or partially edentulous.

- Adult patients 18-60 years of age.

\section{Exclusion criteria include}

1. Infected fracture sites or wounds.

2. Medically compromised patients.

3. Comminuted fractures.

\section{A. Pre-operative phase:}

\section{1) History of the patient}

All patients were presented with mandibular fracture, not more than ten days from the day of trauma. Time, cause, place and type of injury were essential pieces of information as well as past medical and dental history.

\section{2) Clinical examination:}

\section{a) Extra oral examination:}

Inspection: Swelling, ecchymosis, facial deformity, deviation during opening and closing, abnormal movements of the jaw and open bite.

Palpation: Behind of the patient, both sides of the lower border were palpated by the fingers of both hands while the thumbs will be placed on the lateral aspect, starting at the midline, fingers passed posteriorly to assess any step
defects.Any step deformity, alteration in bony contour, tenderness, bony crepition, condylar movement during opening and closing will be assessed.

\section{b) Intra oral examination:}

Inspection: Blood stained saliva will indicate a compound fracture, lingual hematoma is pathognomonic of a fracture involving the lingual plate of the mandible

Inspection of the occlusal plane for the presence of any occlusal abnormality or anystep defects which will be suggestive of fracture of the underlying bone.

Palpation:The buccal and lingual sulci were palpated for the presence of tenderness and alteration of contour.

Palpation of the lips and cheeks, whenever injured for the suspected presence of a tooth or part of tooth or foreign body in the soft tissues.

\section{3) Radiographic examination}

Performed for each patient to confirm the clinical findings, determine the degree and direction of displacement of the fracture segment and locate the fracture line as follows:

Preoperative orthopantomograms, were performed for all the cases, it gives a general survey of both upper and lower jaws, it is especially valuable in detecting mandibular fractures.

Preoperative anterior posterior view (PA), were performed for all the cases, it gives a general survey of both upper and lower jaws, valuable in detecting fractures displacement.

\section{Preoperative preparation[15]}

1. Routine preoperative laboratory investigations (Haemoglobin, Clotting time, Bleeding time, Prothrombin time and activity, Liver and kidney functions and fasting blood sugar).

2. Prophylactic antibiotic Augmentin 1g (Amoxicillin /Clavulanic acid every 12hrs).

3. Chest x-ray and ECG.

4. Preoperative informed consent.

\section{Operative Procedures}

\section{Group A:}

1. General anaesthesia:

- Patient received induction and muscle relaxant then intubated via cuffed naso tracheal tube.

- A pack is applied to prevent any blood, saline and foreign bodies to fall in the airway.

- Patient is put in a hyper-extended neck position after ensuring that patient does not have a cervical spine fractures.

\section{Disinfection, Draping and Toweling:}

Application of upper and lower arch bars or eyelets or combination between them according to needs and IMF.

\section{Gaining access to the fracture site:}

The intraoral mandibular vestibular degloving approach being the most preferred approach was given by making a curvilinear incision $3 \mathrm{~mm}$ apical to the mucogingival junction. Mentalis muscle was exposed and incised perpendicular and deep to the bone, leaving a flap of muscle 


\section{International Journal of Science and Research (IJSR) \\ ISSN (Online): 2319-7064 \\ Index Copernicus Value (2013): 6.14 | Impact Factor (2015): 6.391}

attached to bone for closure. The mucoperiosteal flap was raised carefully keeping the mental neurovascular bundle intact. (Figure 2)

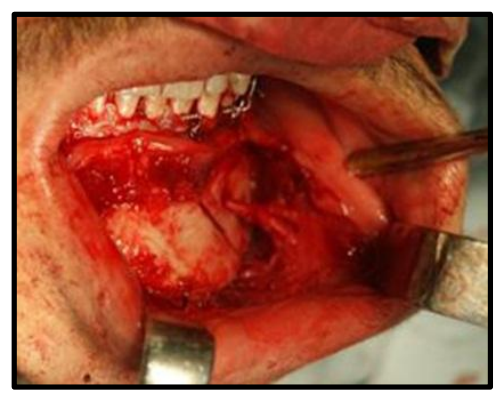

Figure (2): Fracture site.

4. Dissection of mentalis muscle and dissection of mental nerve if needed.

5. Elevation of the periostium.

6. Refreshing of the fracture edges.

7. Intermaxillary fixation after gaining good occlusion.

8. Open reduction and fixation using one 2.0 double $\mathrm{Y}$ shaped " $3 * 3$ " holes with $9 \mathrm{~mm}$ spacing miniplate.

9. Use of monocortical mini-screws $9 \mathrm{~mm}$ in the lower part of the double Y-shaped miniplate.

10. Use of monocortical $7 \mathrm{~mm}$ mini-screws in the upper border of the double Y-shaped miniplate. (Figure 3)

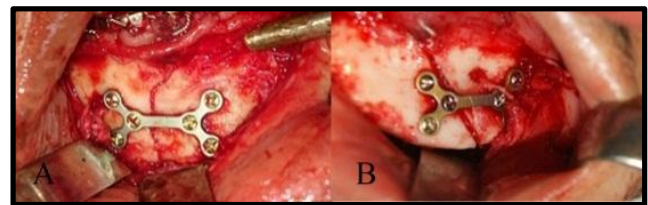

Figure (3): Fixation of plates (double Y).

11. Release of intermaxillary fixation and revaluation of occlusion.

12. The area was irrigated with betadine and saline and after adequate hemostasis was achieved then closure of the wounds in layers without drains.

13. Estimation of the operation time.

\section{Group B:}

Same steps as group (A) with fixation by $2.0 \mathrm{~mm}$ straight mini plates at lower border, $2.0 \mathrm{~mm}$ straight mini plate at upper border and $2.0 \mathrm{~mm}$ mini screws.

\section{Post-operative}

1. Administration of $1 \mathrm{gm}$ of Augmentin (Amoxicillin/Clavulanic acid)every $12 \mathrm{hrs}$ for 7 days.

2. Checking of the occlusion by asking the patient to close in centric occlusion[16].

3. Soft diet will be advised for 1 month.

4. Maintenance of proper oral hygiene with daily irrigation of the oral cavity and use of antiseptic mouth wash will be performed.)

5. Analgesics, anti-inflammatory drugs to control pain and any expected post-operative oedema will be administered.

Clinical follow up:
The patients will be assessed at intervals of one week, 2 weeks and then every month for three month postoperatively for:

\section{a. Pain}

It will be measured through verbal numeric rating scale (VNS)[17]as follows:

$0=\quad$ No pain.

1-3 = Mild pain: It is easily tolerated.

4-6 = Moderate pain: It is causing discomfort but bearable.

7-10 = Severe pain: It is causing discomfort, hardly tolerated and unbearable.

\section{b. Edema}

Edema was evaluated by using the index finger to press on the swelling as deep as possible then approximate the depth in millimeters and the time the indentation takes to return to normal. The result was recorded as using a scale used in patients with edema where[18]:

+1 (Trace): slight indentation, rapid return to normal.

+2 (Mild): $\quad 4 \mathrm{~mm}$ indentation, rebound in few seconds.

+3 (Moderate): $6 \mathrm{~mm}$ indentation, rebound after 10-20 seconds.

+4 (Severe): $\quad 8 \mathrm{~mm}$ indentation and needs $>30$ seconds to return to normal.

\section{c. Trismus}

The maximum interincisal mouth opening (MIMO) was measured using calipers. The measurements were taken after 24 hours then, two, four, six and twelve weeks postoperatively. The results were grouped according the following scale for trismus[19]:

a. Severe trismus MIMO $\leq 15 \mathrm{~mm}$.

b. Moderate trismus $15 \mathrm{~mm} \leq \mathrm{MIMO} \leq 30 \mathrm{~mm}$.

c. Mild trismus $30 \mathrm{~mm} \leq \mathrm{MIMO} \leq 45 \mathrm{~mm}$.

d. Normal MIMO $\geq 45 \mathrm{~mm}$.

\section{d. State of occlusion}

The state of occlusion was checked throughout the postoperative period to ensure the normal occlusion of the patient in terms of molar relation and midline centralization returned to the way it was before injury.

\section{e. Condition of the teeth}

\section{f. Sensory nerve function}

All the patients were assessed preoperatively and postoperatively for subjective symptoms related to the inferior alveolar and mental nerve by asking them about any alteration in sensation in the lower lip and the mandibular teeth on the affected side.

\section{g. Surgical wound}

The wound will be examined for signs of infection including redness, swelling, and discharge.

\section{Radiographic follow up}

The patients will be radiographically assessed immediate postoperatively and then every 1 month for 2 months postoperatively by orthopantomogram and last radiograph with cone beam computerized tomography (CBCT).

It will assess: 


\section{International Journal of Science and Research (IJSR) \\ ISSN (Online): 2319-7064 \\ Index Copernicus Value (2013): 6.14 | Impact Factor (2015): 6.391}

i. The adequacy of reduction of the fractured segments.

ii. The fracture healing progression.

\section{Results}

\section{Preoperative assessment data}

Fourteen patients; divided equally into two groups. six males and 1 females in both groups ; with a ratio of were included in this study. In goup A Patients age were ranging from 18 to 46 years old with a mean of $30.14 \pm 10.73$ and Ingoup B Patients age were ranging from 19 to 58 years old with a mean of $27.43 \pm 13.97$

As regard to the etiology of mandibular fractures in this study, Road traffic accidents were the main etiologic factor representing $85.7 \%$ of cases.The mandibular fractures involved were one symphysealfractures, seven right parasymphseal fractures and six left parasymphseal fractures.

All patients were treated by ORIF using duoble $\mathrm{Y}$ sahpedminiplates for group A and 2 conventional plates for group B , the average time of hospitalization preoperatively was 5 days until oedema subsided, while the average time of hospitalization postoperatively was only 2 day. (Table 1 )

Table 1:Comparison between the two studied groups according to demographic data

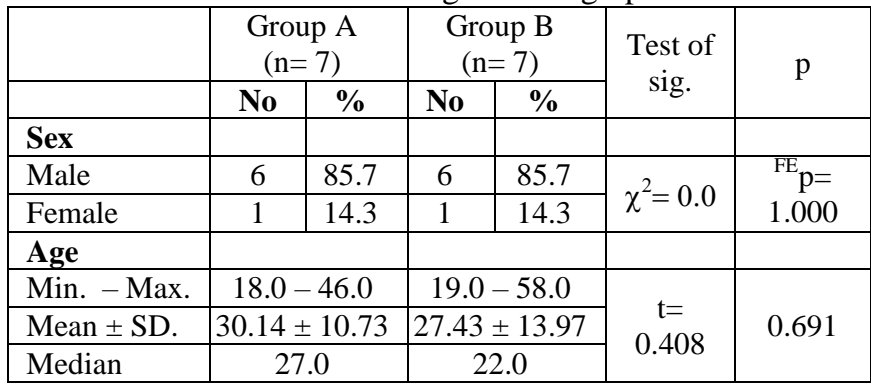

\section{I) Pre-operative data}

- All patients presented with facial asymmetry due to swelling. They also and tenderness on the affected side.

- Eleven patients presented with malocclusion.

- Tweleve patients presented a tooth in the fracture line.

- Four patients presented with mouth deviation to the affected side.

- Three patients presented with IAN/Mental nerve parasthesia.

\section{Postoperative results}

\section{Immediate postoperative results}

\section{Group A}

The patients were seen daily for the first week. As regards oedema, it was limited only to the area adjacent to the fracture site and resolved by the seventh postoperative day.

As regards pain, only one patient suffered persistent pain which lasted for four days but responded after adding one further analgesic dose.
No sensory disturbances were reported in any case except for 1 case that developed mental nerve concusion, but resovled after 3 months.

\section{Group B}

The patients were seen daily for the first week. As regards oedema, it was limited only to the area adjacent to the fracture site and resolved by the seventh postoperative day.

As regards pain, no complaines were detected.

No sensory disturbances were reported in any case except for 2 case that developed mental nerve concusion, but resovled after 3 months.

\section{Delayed postoperative result}

\section{Group A}

- All cases showed stability of the bony segments in the normal position, no mobility of the bony segments was detected.

- No signs of infection or suppuration were observed except in one case that developed infecton related to tooth at fracture line in the first month, but managed with another course of antibiotic and infection was totally resolved.

- All patients showed normal occlusion and intercuspal relations of the teeth with no need for selective grinding.

- The teeth in the fracture line for all the patients remained vital except two patient which had endodontic treatment.

- All cases were able to maintain good oral hygiene by the conventional means through tooth brushing and the use of warm normal saline as a mouthwash.

- The periodontal tissues appeared healthy with no areas of gingival involvement or inflammation.

\section{Group B}

- All cases showed stability of the bony segments in the normal position, no mobility of the bony segments was detected

- No signs of infection or suppuration were observed except in one case that developed infection and discharged pus in the fifth week, but managed with another course of antibiotic and infection was totally resolved.

- All patients showed normal occlusion and intercuspal relations of the teeth with no need for selective grinding.

- The teeth in the fracture line for all the patients remained vital exept one patient witch had endodontic treatment.

- All cases were able to maintain good oral hygiene by the conventional means through tooth brushing and the use of warm normal saline as a mouthwash.

- The periodontal tissues appeared healthy with no areas of gingival involvement or inflammation.

\section{Radiographically}

\section{Group A \& B}

- Immediate postoperative panoramic X-ray, showed satisfactory reduction in all cases proper bony alignment at the lower border of the mandible without noticeable 


\section{International Journal of Science and Research (IJSR) \\ ISSN (Online): 2319-7064}

Index Copernicus Value (2013): 6.14 | Impact Factor (2015): 6.391

step and proper teeth alignment with no sign of any periapical infection.

- After one month, the panoramic views showed stable fracture segments in all cases.

- After two month, the panoramic views showed normal trabeculation of the bone as compared with the adjacent bone.

After three month, the Cbct views showed good healing in the fracture site.

\section{1- Pain}

Show the pain intensity scores at the fracture site preoperatively, 24 hours, 1 week, 2 weeks, 1 month and 2 month and 3 month afterminiplate placement.Pain intensity was significantly decreased in all cases across the follow up period where mean Pain intensity scores after 24 hours, one week, two weeks, one month, two months and three months follow up period were found to be statistically significant as $\mathrm{p}$ value were $0.039,0.017,0.028,0.018,0.016,0.017$ respectively $(\mathrm{p} \leq 0.05)$ for the both groups (Table 2$)$.

Table 2: Comparison betweenn the two studied groups according pain

\begin{tabular}{|c|c|c|c|c|c|c|c|}
\hline & \multicolumn{7}{|c|}{ Pain (Score 0-10) } \\
\hline Group A & Pre & One day & 1 week & 2 weeks & 4 weeks & 6 weeks & 12weeks \\
\hline Min. - Max. & $7.0-10.0$ & $5.0-9.0$ & $3.0-7.0$ & $0.0-7.0$ & $0.0-3.0$ & $0.0-1.0$ & $0.0-0.0$ \\
\hline Mean \pm SD. & $8.57 \pm 0.98$ & $7.29 \pm 1.38$ & $5.29 \pm 1.60$ & $3.0 \pm 2.52$ & $1.14 \pm 1.46$ & $0.14 \pm 0.38$ & $0.0 \pm 0.0$ \\
\hline Median & 9.0 & 8.0 & 6.0 & 3.0 & 0.0 & 0.0 & 0.0 \\
\hline Group B & & & & & & & \\
\hline Min. - Max. & $8.0-10.0$ & $6.0-9.0$ & $3.0-7.0$ & $0.0-7.0$ & $0.0-3.0$ & $0.0-1.0$ & $0.0-0.0$ \\
\hline Mean \pm SD. & $8.86 \pm 0.90$ & $7.43 \pm 1.27$ & $5.86 \pm 1.35$ & $3.14 \pm 2.91$ & $1.14 \pm 1.46$ & $0.14 \pm 0.38$ & $0.0 \pm 0.0$ \\
\hline Median & 9.0 & 7.0 & 6.0 & 3.0 & 0.0 & 0.0 & 0.0 \\
\hline $\mathbf{Z}$ & 0.471 & 0.131 & 0.787 & 0.066 & 0.0 & 0.0 & 0.0 \\
\hline $\mathbf{p}$ & 0.638 & 0.896 & 0.431 & 0.947 & 1.000 & 1.000 & 1.000 \\
\hline
\end{tabular}

\section{Edema}

All patients developed edema postoperatively. They were started on anti-edematous medication and advised to apply cold fomentation for the first 24 hours. No bandage was used postoperatively to reduce edema.

\section{Group A}

The edema resolved on treatment such that by the end of one week only two had mild edema. After two weeks $90 \%$ of the patients had trace levels or no edema at all. By the end of the fourth week edema had resolved in majority of the patients. By the end of twelve weeks all patients were free of swelling and facial asymmetry. Decreasing edema after one week, four weeks, six weeks and twelve weeks follow up period was found to be statistically significant as $\mathrm{P}$ value was $0.015(\mathrm{P} \leq 0.05)$.

\section{Group B}

The edema resolved on treatment such that by the end of one week only one had mild edema. After two weeks $90 \%$ of the patients had trace levels or no edema at all. By the end of the fourth week edema had resolved in majority of the patients. By the end of twelve weeks all patients were free of swelling and facial asymmetry. Decreasing edema after one week, four weeks, six weeks and twelve weeks follow up period was found to be statistically significant as $\mathrm{P}$ value was $0.016(\mathrm{P} \leq 0.05)$. (Table 3)

Table 3:Comparison between the two studied groups according edema

\begin{tabular}{|c|c|c|c|c|c|c|c|}
\hline & \multicolumn{7}{|c|}{ Edema Score (0-4) } \\
\hline & Pre & One day & 1 week & 2 weeks & 4 weeks & 6 weeks & 12weeks \\
\hline Group A & & & & & & & \\
\hline Min. - Max. & $3.0-4.0$ & $3.0-4.0$ & $2.0-3.0$ & $1.0-2.0$ & $0.0-1.0$ & $0.0-0.0$ & $0.0-0.0$ \\
\hline Mean \pm SD. & $3.57 \pm 0.53$ & $3.14 \pm 0.38$ & $2.29 \pm 0.49$ & $1.29 \pm 0.49$ & $0.14 \pm 0.38$ & $0.0 \pm 0.0$ & $0.0 \pm 0.0$ \\
\hline Median & 4.0 & 3.0 & 2.0 & 1.0 & 0.0 & 0.0 & 0.0 \\
\hline Group B & & & & & & & \\
\hline Min. - Max. & $2.0-4.0$ & $3.0-4.0$ & $2.0-3.0$ & $1.0-2.0$ & $0.0-1.0$ & $0.0-0.0$ & $0.0-0.0$ \\
\hline Mean \pm SD. & $3.14 \pm 0.69$ & $3.57 \pm 0.53$ & $2.57 \pm 0.53$ & $1.43 \pm 0.53$ & $0.29 \pm 0.49$ & $0.0 \pm 0.0$ & $0.0 \pm 0.0$ \\
\hline Median & 3.0 & 4.0 & 3.0 & 1.0 & 0.0 & 0.0 & 0.0 \\
\hline Z & 1.214 & 1.612 & 1.041 & 0.537 & 0.628 & 0.0 & 0.0 \\
\hline $\mathbf{p}$ & 0.225 & 0.107 & 0.298 & 0.591 & 0.530 & 1.000 & 1.000 \\
\hline
\end{tabular}

\section{Occlusion disturbance}

Show the occlusal disturbance postoperatively 24 hours, 1 week, 2 weeks, 1 month and 2 month and 3 month after miniplate placement.Occlusion disturbance was significantly came to normal in all cases across the follow up period where occlusion disturbance scores after 24 hours, one week, two weeks, one month, two months and three months follow up period were found to be statistically significant as $\mathrm{p}$ value were $<0.016$ across the whole follow up period $(\mathrm{p}<$ 0.05 ) for both groups

\section{Maximum mouth opening}

Show the maximum mouth opening scores preoperatively, 24 hours, 1 week, 2 weeks, 1 month and 2 month and 3 month after miniplate placement where maximum mouth opening measured in mm.Maximum mouth opening was significantly increased in all cases across the follow up

\section{Volume 5 Issue 7, July 2016 www.ijsr.net}




\section{International Journal of Science and Research (IJSR) \\ ISSN (Online): 2319-7064 \\ Index Copernicus Value (2013): 6.14 | Impact Factor (2015): 6.391}

period where mean maximum mouth opening after 24 hours, one week, two weeks, one month, two months and three months follow up period were found to be statistically significant as $\mathrm{p}$ value were $<0.001(\mathrm{p}<0.05)$ for both groups.

\section{Step deformity}

Show the step deformity at the fracture site postoperatively 24 hours, 1 week, 2 weeks, 1 month and 2 month and 3 month after miniplate placement.Step deformity was significantly disappeared in all cases across the follow up period where step deformity scores after 24 hours, one week, two weeks, one month, two months and three months follow up period were found to be statistically significant as $\mathrm{p}$ value were $<0.016$ across the whole follow up period $(\mathrm{p}<0.05)$ for both groups. (Figure 4, 5)



Figure 4: Panorama postoperative

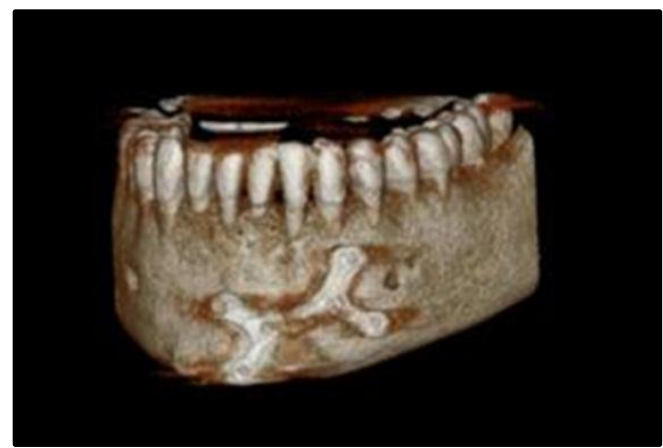

Figure 5: CBCT postoperative

\section{Discussion}

The treatment of these mandibular fractures has changed dramatically in recent years. Traditional 6-week treatment of closed reduction with MMF or open reduction with wire osteosynthesis and MMF has given way to ORIF osteosynthesis techniques with early mobilization and restoration of jaw function, improved airway control, improved nutrition, improved patient comfort and hygiene, and an earlier return to work[20,21]. However, open reduction and internal fixation of anterior mandibular fracture has been associated with the lowest incidence of complications compared to other parts of the mandible ,Most of these complications have been associated with malocclusion, wound infection, dental injury and plate exposure[22].

Different shaped of titanium mini plates have been used widely by surgeons for fixation of the facial truma region.
Its use in the maxilla,Only recently Hughes extended its use to the mandible[23-25].Most of the studies about using semi rigid fixation by using different shaped mini plates system in mandibular fracture shows the plates should be strong yet malleable facilitating stabilization both at superior and inferior borders. concluded single mini titanium plates are an easy to use alternative to conventional mini plates but contraindicated its use in fractures with less inter fragmentary bone contact[23, 25-30].

The clinical effectiveness of shaped mini plates needs to be verified or substantiated by biomechanical studies. ERGUN et $\mathrm{al}[14]$ in there biomechanical experiment found that the Double Y-shaped titanium mini plate with 6 holes and 9.0 $\mathrm{mm}$ spacing had greater resistance to displacement and provided more favorable biomechanical behavior than the other types of shaped miniplates in the repair of mandibular body fractures.

The age distribution of the patients was being in the 19-53 age group with a mean of years, this was in agreement with Subhashraj et al [3] andongodia et al [1] Who reported age range 1-72 years with a mean of 28.5, it is thought that this result is due to the fact that in our country the young adults present a large mass and are the main mobile segment of population who participate in out-side activities.

Incidence of mandibular fractures in males compared with that of females was, this was in accordance with WakulobaGet al [17]. The low female incidence in this study could be attributed to the fact that women in our country do not participate in the same physical activities and are less exposed to violence as men are and thus are less exposed to trauma.Regard to the etiology of mandibular fractures in this study, Road traffic accidents were the main etiologic factor representing $85.7 \%$ of cases and this was found to be in agreement with Subhashraj et al[3] and Sakr et al [6]who supporting reported Road traffic accidents around $39 \%$ to $72 \%$ of fractures of the mandible. On the other hand, other ShreyaVerma and Ian Chambers [31] found assault main etiologic factor representing $61 \%$.

And regard the site of fracture: cases in this study were one symphysealfractures and thirteen parasymphyseal fractures. The degree of displacement in mandibular fracture is a key elements in determination of the favorability of the fracture and significantly affects healing outcomes. Juergen and Guimond reported $46 \%$ to $80 \%$ of their study subjects to have minimally displaced mandibular fractures [13, 32] However in this study, $60 \%$ of the mandibular fractures were moderately displaced.

The time taken for fixation directly reflects the difficulty in placement of a particular plate. The time of mini plates fixation is calculated from the beginning of plate adaptation to placement of the last screw. Various surgeons have reported reduced operating time with the usage of a single plate. As the double Y shaped mini plate is a single plate, less screws are used in fixation (6 screws) compared to using two conventional plates which will consume between 8 to 10 screws, hence increasing the time spent to adapt the plates and complete fixation. Feledy and Hughes mentioned that the easier application of 3D single plates was reflected in a reduced average operating time[33, 34]. 


\section{International Journal of Science and Research (IJSR) \\ ISSN (Online): 2319-7064}

Index Copernicus Value (2013): 6.14 | Impact Factor (2015): 6.391

The time taken for double $\mathrm{Y}$ - shaped plate adaptation to definitive fixation in this study ranged from 10 to $12 \mathrm{~min}$. It was a significantly faster fixation time compared to conventional mini plates used in the study.

Pain intensity was significantly decreased in all cases across the follow up period. Adequate stabilization of the fracture segments that does not allow them to move apart eliminates the pain at the fracture site and promotes good oral hygiene for the surgical wound area. This is in agreement with Wakuloba $G$ et al[17]which mentioned that pain has been eliminated at the end of the $2^{\text {nd }}$ week post operatively

There was no post operativeocclusal disturbances in the majority of the cases in this study due to adequate stabalization of the fractured segments and absence of any other associated fractures, although there were two cases in group A that involved more than one fracture pattern and showed no occlusal disturbance as well. This was in disagreement with Ellis et al[35] who stated that Because the second fracture changes the biomechanics acting across the fractures, it is possible that single titanium miniplates applied to both fractures cannot counter the more complex forces working on the dentoosseous fragment between the 2 fractures.

Mandibular fracture fixation has had its share of complications in the form of bone and soft tissue infection, malunion, delayed union, non union, plate fracture and most importantly malocclusion. The studies showed complication rates of miniplateosteosynthesis for mandibular fractures treatment ranges approximately from $3.8 \%$ to $28 \%$ over the last three decades[1, 36-39]. In this study two patient having mandibular parasymphyseal fracture developed infection in first month, one patient in the form of purulent material discharge from the intraoral wound which was managed with intravenous antibiotics. And other one with preapical infection in the tooth at the fracture line which accepted to endodontic treatment, No one $(0 \%)$ developed trismus or malunion or malunion or malocclusion.

\section{Conclusions}

From the results of this study it was concluded that:

1. The use of double Y-shaped mini plate is a successful method in fixation of anterior mandibular fracture.

2. It has been shown that double Y- shaped mini plates have same stabilization due to it's configuration as conventional mini plates in fixation of simple anterior mandibular fractures.

3. Eliminates the need for placing 2 miniplates in the anterior area of the mandible as it has a shape double Y sharing load angle with interconnecting struts.

4. The use of double Y- shaped miniplate less traumatic of the bone by using 6 screws in fixation.

5. The use of double $\mathrm{Y}$ - shaped miniplate reduces cost on the patient.

6. The use of double $\mathrm{Y}$ - shaped miniplate reduces time of the operation because easy manipulated and applied.

\section{References}

[1] Ongodia D. Comparative analysis of trends in the treatment of mandibular fractures. J Oral Maxillofac Surg Med Pathol 2014;26: 276-9.

[2] Ogundare BO, Bonnick A, Bayley N. Pattern of mandibular fractures in an urban major trauma center. $\mathbf{J}$ Oral Maxillof Surg 2003; 61: 713-8.

[3] Krishnaraj S, Chinnasamy R. A 4-year retrospective study of mandibular fractures in a South Indian city. J Craniofac Surg 2007; 18: 776-80.

[4] Atilgan S, Erol B, Yaman F, Yilmaz N, Ucan MC. Mandibular fractures: a comparative analysis between young and adult patients in the southeast region of Turkey. J Appl Oral Sci 2010; 18: 17-22.

[5] Qudah MA, Al-Khateeb T, Bataineh AB, Rawashdeh MA. Mandibular fractures in Jordanians: a comparative study between young and adult patients. J Craniomaxillofac Surg 2005; 33: 103-6.

[6] Sakr K, Farag IA, Zeitoun IM. Review of 509 mandibular fractures treated at the University Hospital, Alexandria, Egypt. Br J Oral Maxillofac Surg 2006; 44: 107-11.

[7] Ugboko V, Odusanya S, Fagade O. Maxillofacial fractures in a semi-urban Nigerian teaching hospital: A review of 442 cases. Int J Oral Maxillofac Surg 1998; 27: 286-9.

[8] Adebayo ET, Ajike O, Adekeye E. Analysis of the pattern of maxillofacial fractures in Kaduna, Nigeria. Br JOral Maxillofac Surg 2003; 41: 396-400.

[9] Dingman RO, Natvig P. Occlusion and intermaxillary fixation. Surgery of Facial Fractures. Philadelphia: WB Saunders, 1964. 111-31.

[10] Brons R, Boering G. Fractures of the mandibular body treated by stable internal fixation: a preliminary report. J Oral Surg 1970; 28: 407-15.

[11] Champy M, Loddé JP, Schmitt R, Jaeger JH, Muster D. Mandibular osteosynthesis by miniature screwed plates via a buccal approach. J Maxillofac Surg 1978; 6: 14-21.

[12] Kalfarentzos EF, Deligianni D, Mitros G, Tyllianakis M. Biomechanical evaluation of plating techniques for fixing mandibular angle fractures: the introduction of a new 3D plate approach. Oral Maxillofac Surg2009; 13: 139-44.

[13] Claude G, Johnson JV, Marchena JM. Fixation of mandibular angle fractures with a 2.0-mm 3dimensional curved angle strut plate. J Oral Maxillofac Surg 2005; 63: 209-14.

[14] Ergun S, Ofluoğlu D, Saruhanoğlu A, Karataşli B, Deniz E, Özel S, et al. Comparative evaluation of various miniplate systems for the repair of mandibular corpus fractures. Dental Mater J2014; 33: 368-72.

[15]Lizuka TLC. Rigid intemal Fixation of mandibular fractures. J Oral Maxillofac Surg 1992; 21: 65-6.

[16]Peter ED. Evaluation, Diagnosis, and Treatment of Occlusal Problems. Ch. 27.UK: Mosby, 470-6.

[17] Wakuloba G, Mahallawy A, Ragab H.Evaluation of dynamic compression miniplates in treatment of mandibular angle fractures using trocar. Alex Dent $\mathbf{J}$ 2015; 40: 86-93.

[18] Kindermann M, Meyer T, Kindermann W, Nickenig G. Exercise training in heart failure. Herz 2003; 28: 15365. 


\section{International Journal of Science and Research (IJSR) \\ ISSN (Online): 2319-7064}

Index Copernicus Value (2013): 6.14 | Impact Factor (2015): 6.391

[19] Rieder CE. Maximum mandibular opening in patients with and without a history of TMJ dysfunction. J Prosthet Dent 1978; 39: 441-6.

[20]Fonseca RJ. Oral and maxillofacial trauma. Vol. 2. Missouri: Elsevier Health Sciences, 2013.

[21] Sorel B. Open versus closed reduction of mandible fractures. Oral Maxillofac Surg Clin North Am 1998; 10: 541-66.

[22]Lee T, Sawhney R, Ducic Y. Miniplate fixation of fractures of the symphyseal and parasymphyseal regions of the mandible: A review of 218 patients. JAMA Facial Plastic Surg 2013; 15: 121-5.

[23] Khalifa ME, El-Hawary HE, Hussein MM. Titanium three dimensional miniplate versus conventional titanium miniplate in fixation of anterior mandibular fractures. Life Sci J 2012; 9: 1006.

[24] Korkmaz HH. Evaluation of different miniplates in fixation of fractured human mandible with the finite element method. Oral Surg Oral Med Oral Pathol Oral Radiol Endodontology 2007; 103: e1-e13.

[25] Pilling E, Eckelt U, Loukota R, Schneider K, Stadlinger B. Comparative evaluation of ten different condylar base fracture osteosynthesis techniques. $\mathrm{Br} \mathrm{J}$ Oral Maxillofac Surg 2010; 48: 527-31.

[26] Arbag H, Korkmaz HH, Ozturk K, Uyar Y. Comparative Evaluation of Different Miniplates for Internal Fixation of Mandible Fractures Using Finite Element Analysis. J Oral Maxillofac Surg 2008; 66: 1225-32.

[27] Madsen MJ, McDaniel CA, Haug RH. A Biomechanical Evaluation of Plating Techniques Used for Reconstructing Mandibular Symphysis/Parasymphysis Fractures. J Oral Maxillofac Surg 2008; 66: 2012-9.

[28] Wang H, Ji B, Jiang W, Liu L, Zhang P, Tang W, Fan, Y. Three-Dimensional Finite Element Analysis of Mechanical Stress in Symphyseal Fractured Human Mandible Reduced With Miniplates During Mastication. J Oral Maxillofac Surg 2010; 68: 1585-92.

[29] Saluja H, Kini Y, Mahindra U, Kharkar V, Rudagi BM, Dehane V. A comparative evaluation of different treatment modalities for parasymphysis fractures: a pilot study. Int J Oral Maxillofac Surg 2012; 41: 906-11.

[30] Saluja H, Dehane V, Kini Y, Mahindra U, Gaikwad P. Use of Miniplates in Parasymphysis Fractures: A Survey Conducted Among Oral and Maxillofacial Surgeons of India. J Maxillofac Oral Surg 2013; 12: 312-4.

[31] Verma S, Chambers I, Update on patterns of mandibular fracture in Tasmania, Australia. Br J Oral Maxillofac Surg 2015; 53: 74-7.

[32]Zix J, Lieger O, Iizuka T. Use of straight and curved 3dimensional titanium miniplates for fracture fixation at the mandibular angle. J Oral Maxillofac Surg 2007; 65: 1758-63.

[33] Feledy J, Caterson EJ, Steger S, Stal S, Hollier L. Treatment of mandibular angle fractures with a matrix miniplate: a preliminary report. Plast Reconstr Surg2004; 114: 1711-6.

[34] Hughes P. 3D plate versus the lag screw technique for treatment of fractures of the anterior mandible. J Oral Maxillofac Surg 2000; 58: 23.

[35]Ellis III E. Open Reduction and Internal Fixation of Combined Angle and Body/Symphysis Fractures of the
Mandible: How Much Fixation Is Enough? J Oral Maxillofac Surg 2013; 71: 726-33.

[36] Cawood J. Small plate osteosynthesis of mandibular fractures. Br J Oral Maxillofacial Surgery 1985; 23: $77-$ 91.

[37] Michelet FX, Deymes J, Dessus B. Osteosynthesis with miniaturized screwed plates in maxillo-facial surgery. J Maxillofac Surg 1973; 1: 79-84.

[38] Champy M, Loddé JP, Schmitt R, Jaeger JH, Muster D. Mandibular osteosynthesis by miniature screwed plates via a buccal approach. J Maxillofac Surg 1978; 6: 1421.

[39] Schortinghuis J, Bos RKM, Vissink A. Complications of internal fixation of maxillofacial fractures with microplates. J Oral Maxillofac Surg 1999; 57: 130-4.

\section{Author Profile}

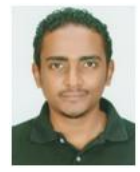

Mohamed SalaheldinKhairi, received the B.D.S. In Dental and Oral Surgery from Liaquat University of Medical \& Health Sciences, Jamshoro - Pakistan 2009. During 2009-2010,he practiced in Ministry of HealthLiaquat University hospital. Since 2011 till now, he is a Visitor resident doctor in oral and maxillofacial surgery department, Faculty of Dentistry, Alexandria University. During 2012-2016, he educated for M.S degree in oral and maxillofacial surgery department, Faculty of Dentistry. Alexandria University ,email:dr.mohamedkhairi@gmail.com

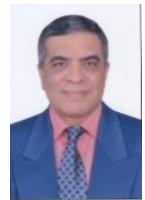

Nagy Elprince Hassan, B.D.S., M.Sc., $\mathrm{PhD}$.Professor of Oral \& Maxillofacial Surgery, Faculty of Dentistry, Alexandria University.

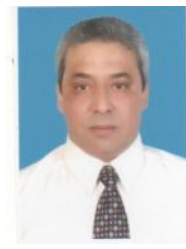

Magued Hussein Fahmy, B.D.S., M.Sc., PhD.,Professor of Oral \& Maxillofacial Surgery, Faculty of Dentistry, Alexandria University.Consultant of oral surgery in DR MOHAMED FAKHRY hospital, AL-KHOBAR Saudi Arabia from 1993_1998, Consultant of oral surgery in EL HAYAT medical center, Kuwait from 2007- 2011.General supervisor of all dental centers in all university hospitals, Alexandria university since march 2015 till today.fmagued@yahoo.com 